\title{
O PAPEL DAS REPRESENTAÇÕES SOCIAIS NA CONSTRUÇÃO DA IDENTIDADE DOCENTE
}

\author{
Mayara Aparecida Pereira Menezes, Augusta Boa Sorte Oliveira Klebis, Raimunda Abou Gebran
}

Universidade do Oeste Paulista - UNOESTE, Presidente Prudente, SP. E_mail: mayara_pmenezes@hotmail.com.br, augusta@unoeste.br, ragebran@hotmail.com

\section{RESUMO}

O presente artigo se constitui parte de uma pesquisa intitulada "Ser professor no século XXI: as representações sociais de alunos ingressantes e concluintes de um curso de pedagogia", com apoio do $\mathrm{PIBIC/CNPq/UNOESTE}$. Trata-se, nessa primeira fase, de uma pesquisa bibliográfica que se propõe trazer para o debate o papel das representações sociais na construção da identidade docente e de como a formação inicial pode contribuir nesse processo. Faz-se necessário discutir a influência das representações sociais no processo de construção da identidade docente, devido ao papel que estas exercem na orientação de condutas e de práticas sociais. Ademais, o estudo das representações sociais pode ser um caminho promissor para atingir os propósitos educacionais. Pretende-se assim, ressaltar a importância da formação inicial para a construção da identidade e profissionalidade docente, de modo a possibilitar um diálogo permanente com a realidade do espaço escolar, em especial da escola básica pública.

Palavras-Chave: Formação de Professores. Identidade Docente. Representações Sociais. Formação Inicial

\section{THE ROLE OF SOCIAL REPRESENTATIONS IN CONSTRUCTION OF IDENTITY TEACHER}

\section{ABSTRACT}

This article is part of a research entitled "Being a teacher in the XXI century: the social representations of students entering and graduating from a course in pedagogy", with support from PIBIC / CNPq / UNOESTE. It is in this first phase, a literature that aims to bring to the debate the role of social representations in the construction of teacher identity and how the initial training can contribute to this process. It is necessary to discuss the influence of social representations in the teaching identity construction process, due to the role they play in guiding behavior and social practices. Furthermore, the study of social representations may be a promising way to achieve educational purposes. The aim is to, emphasize the importance of initial training for the construction of identity and the teaching profession in order to facilitate an ongoing dialogue with the reality of the school environment, in particular the basic school.

Keywords: Teacher Education. Teacher identity. Social Representations. Initial formation

\section{INTRODUÇÃO}

Torna-se cada vez mais evidente o desestímulo dos jovens à escolha do magistério como profissão futura e a desmotivação dos professores em exercício para buscarem aprimoramento profissional. Esse quadro é consequência, sobretudo, das más condições de trabalho a que são submetidos os docentes, com baixos salários, jornada de trabalho excessiva, planos de carreira não condizentes com as necessidades atuais ou até a sua inexistência e, em especial, com relação ao desprestígio social e a imagem depreciativa veiculada pela mídia. Nesse contexto, Imbérnon (2009) coloca como um grande desafio da atualidade tornar a profissão docente mais atrativa, seja na entrada, seja durante o seu percurso.

Por outro lado, várias pesquisas apontam que a exigência de uma educação de qualidade é fator prioritário para o desenvolvimento econômico e social de um país e que tal exigência não pode estar dissociada de um processo de valorização docente. Processo esse que implica em pensar em uma formação inicial e continuada, que permita aos professores se apropriarem de competências e saberes imprescindíveis a uma atuação profissional transformadora. 
Dessa forma, torna-se relevante 0 compromisso das políticas públicas e das instituições formadoras em qualificar um grande número de educadores e futuros profissionais da educação para uma população escolar crescente, que apresenta sérias defasagens em relação aos conhecimentos básicos necessários á sua emancipação social.

Não podemos desconsiderar ainda que o momento histórico impõe aos docentes, conforme ressalta Morgado (2005, p. 67) o grande desafio "de desenvolver uma educação multicultural e antidiscriminatória, que permita a integração de valores, ideias, tradições e costumes muito distintos, que atenda à diversidade e pluralidade dos cidadãos e estimule e reflexão crítica e a tolerância".

Requer, portanto, uma formação docente ampliada, que vá além das competências historicamente atribuídas aos professores, ou seja, que a complexidade da ação docente se encontre atrelada às exigências da atual sociedade.

Nesse sentido, cabe aqui ressaltar a importância da formação inicial para a construção da identidade e profissionalidade docente, de modo a possibilitar um diálogo permanente com a realidade do espaço escolar, em especial da escola básica pública.

Vale lembrar que a identidade docente é uma construção social, pois se constitui na relação dialética entre as dinâmicas das relações sociais e a experiências de vida de cada indivíduo. Trata-se de uma construção articulada na subjetividade e na objetividade de suas relações sociais.

Assim, pode-se afirmar que a formação inicial atua como um processo identitário, quando possibilita, ao futuro docente, construir conhecimentos relativos à profissão e vivenciar, por meio do estágio supervisionado, o contato com a escola básica, em um processo da articulação que lhe permitirá produzir sentidos sobre a profissão docente, bem como refletir e agir sobre ela.

Entender o processo de constituição da identidade docente, passa pela compreensão de que ela foi sendo constituída por múltiplos contextos: sociais, históricos, culturais e políticos, dentre outros. É necessário considerar que esse processo de identificação com uma profissão por um determinado grupo é um fenômeno histórico, portanto, como tal, está sujeito a transformações. Para Ciampa (2007) a identidade não é um dado pronto ou cristalizado, ela é processo, é metamorfose que tende à emancipação.

Contudo, observa-se que ao tentar compreender a natureza do trabalho docente nos deparamos com as representações que a sociedade possui a respeito da escola e do professor, estimuladas, em muitos casos, por representações engendradas por políticas educacionais e econômicas, com a finalidade de construir uma identidade docente reprodutora das aspirações desse sistema.

Nesse sentido, esta pesquisa busca discutir o papel das representações sociais na construção da identidade docente e como a formação inicial poderá contribuir para o fortalecimento desse processo, rumo a uma profissionalidade que atenda aos desafios atuais da docência.

\section{A Teoria das Representações Sociais: Fundamentação Teórica}

As representações sociais estão presentes em nosso meio comum, tanto no cotidiano em que interagimos e nos relacionamos, como também na mídia que lemos, olhamos, ouvimos. Deste modo, as representações sociais mantidas fortemente pelas influências sociais da comunicação formam as realidades de nossas vidas, além de contribuírem como principal elo para estabelecer conexões pelas quais nós nos relacionamos e interligamos uns aos outros.

Segundo Moscovici, "as representações sociais são entidades quase tangíveis. Elas circulam, se entrecruzam e se cristalizam continuamente, através duma palavra, dum gesto, ou duma reunião, em nosso mundo cotidiano" $(2015$, p.10). Elas nos guiam na forma como nomeamos e definimos em conjunto os diversos aspectos de nossa realidade, bem como no modo de interpretar, de entender, de ter um ponto de vista e defendê-lo.

$\mathrm{O}$ autor considera que as representações sociais são teorias do senso comum que são produzidas coletivamente nas interações sociais, sujeito-sujeito e sujeito-instituição, cada qual no seu tempo, cultura e espaço específico, a fim de transformar o que é estranho em familiar, para assim compreender a realidade. Salienta que é por meio das interações com o mundo e com os sujeitos que elaboramos o conhecimento, fortalecemos nossa socialização, construímos valores e nos apropriamos de ideias que circulam 
na sociedade (MOSCOVICI, 1978 apud GEBRAN; TREVIZAN, 2017, no prelo)

Do mesmo modo, na definição de Jodelet (2001), as representações sociais são fenômenos complexos que sempre estão ativos e atuando em nossa vida cotidiana. Para a autora, as representações sociais são identificadas como sistemas de interpretação, os quais orientam nossas relações com o mundo e com as pessoas, de tal modo que direciona e coordena as condutas e as comunicações sociais, além de interferir em diversos processos, como na transmissão e assimilação de conhecimentos, nas transformações sociais, no estabelecimento de identidades pessoais bem como sociais e expressões grupais.

Ademais, Jodelet (2001, p. 22) suscita que as representações sociais:

como fenômenos
cognitivos, envolvem a
pertença social dos
indivíduos às implicações
afetivas e normativas, com
as interiorizações de
experiências, práticas,
modelos de conduta e
pensamento, socialmente
inculcados ou transmitidos
pela comunicação social,
que a ela estão ligados.

Nesta perspectiva, tal estudo contribui significativamente para a compreensão de que a vida intelectual, individual e coletiva se encontram interligadas. Para a autora, as representações sociais são abordadas ao mesmo tempo, como produto e como processo de uma atividade de apropriação da realidade exterior ao pensamento e da elaboração psicológica e social da realidade.

De acordo com Jodelet:

representar ou se
representar corresponde a
um ato de pensamento
pelo qual o sujeito se
reporta a um objeto,
quanto a uma pessoa,
quanto uma coisa, um
acontecimento material,
psíquico ou social, um
fenômeno natural, uma
ideia, uma teoria etc.;
pode ser tanto real quanto
imaginário ou mítico, mas
é sempre necessário. Não
há representação sem

objeto. Não há representação sem objeto (2001, p.22).

Nesse sentido, representação se configura como a representante mental do objeto que reorganiza, simbolicamente. Por outro lado, leva a marca do sujeito e de suas ações. Assim, as atitudes do sujeito dizem respeito ao caráter construtivo, criativo, autônomo da representação que contém uma parte de reconstrução, de interpretação do objeto e de expressão do sujeito.

Conforme Jodelet (2001), as representações sociais com toda sua riqueza, fazem emergir diversos elementos constituintes da vida social, os quais podem ser informativos, ideológicos, cognitivos, normativos, valores, crenças, atitudes, opiniões, imagens etc., tais elementos são sempre organizados como uma espécie de saber que diz alguma coisa sobre o estado da realidade.

Ainda complementando essa ideia, Moscovici (apud JODELET, 1993, p. 4-5) expõe que a representação social "é uma forma de conhecimento, socialmente elaborado e compartilhado, que tem um objetivo prático e concorre para a construção de uma realidade comum a um conjunto social". Ressalta também que é um 'saber do senso comum', 'saber ingênuo', distinguindo-se assim do conhecimento científico.

Resultado da interação e comunicação, as representações sociais se formam e se configuram a qualquer instante, como consequência do equilíbrio específico dos processos de influência social. Nesse sentido, Moscovici define-as como:

Um sistema de valores, ideias e práticas, com uma dupla função: primeiro, estabelecer uma ordem que possibilitara às pessoas orientar-se em seu mundo material, e social e controlá-lo; e em segundo lugar, possibilitar que a comunicação seja possível entre os membros de uma comunidade, fornecendo-lhes um código para nomear e classificar, sem ambiguidade, os vários aspectos de seu mundo e 
da sua história individual e social $(2015$, p. 21$)$.

Duveen (2015) comenta que, se por um lado as representações podem ser produtos da comunicação, por outro, sem a representação não seria possível a comunicação. E que, devido a essa interligação, as representações podem alterar a estabilidade de sua organização e estrutura, dependendo da coerência, credibilidade e tratamento dos padrões de comunicação que as mantem. Ainda complementa dizendo que "a mudança dos interesses humanos pode gerar novas formas de comunicação, resultando na inovação e emergência de novas representações" (2015, p. 22).

Moscovici argumenta que "o propósito de toda representação é tornar algo não familiar, ou a própria não familiaridade em familiar" (2015, p.20). A familiaridade é um processo construtivo de ancoragem e objetivação, pelo qual, o não familiar passa a ocupar um lugar em nosso mundo já familiarizado.

Diante disso, se as representações sociais servem para familiarizar o não familiar, o primeiro trabalho que deve ser realizado em um estudo científico das representações é fazer com que o não familiar se torne familiar, para que assim, possam ser compreendidas como fenômenos e descritas por meio de técnicas metodológicas adequadas a cada situação (DUVEEN, 2015). Neste aspecto, "a teoria das representações sociais fornece 0 referencial interpretativo tanto para tornar as representações visíveis como para torná-las inteligíveis como formas de prática social" (p.25).

\subsection{A natureza das representações sociais}

De acordo com Moscovici (2015) as representações possuem duas funções: convencional e prescritiva. A primeira função é convencionalizar objetos, pessoas, ou acontecimentos que encontrar. Elas os moldam, e gradualmente os ajustam como modelo de determinado tipo, distinto e compartilhado por um grupo de pessoas. Tais convenções nos permitem identificar o que representa o quê. Nos ajudam ainda a solucionar a questão de saber o momento de interpretar uma mensagem como importante, ou quando um acontecimento é insignificante ou casual. Diante disso, Moscovici, salienta que: nenhuma mente está livre

dos efeitos de condicionamentos

anteriores que lhes são impostos por suas representações,

linguagem ou cultura. Nós pensamos através de uma linguagem; nós organizamos nossos pensamentos, de acordo com um sistema que está condicionado, tanto por nossas representações, como por nossa cultura. Nós vemos apenas o que as convenções subjacentes nos permitem ver e nós permanecemos

inconscientes dessas convenções (2015, p. 35).

Entretanto, há a possibilidade de conscientização a respeito do aspecto convencional da realidade, para desviarmos de certas exigências que ela impõe em nossa mente. Moscovici (2015) comenta que melhor do que evitar todas as convenções, uma melhor estratégia apontada, seria descobrir e mostrar uma única representação. Assim, em vez de negar tais convenções e preconceitos, essa estratégia nos permitirá o reconhecimento de que as representações formam um tipo de realidade. Deste modo, não vamos negar as convenções e os preconceitos, mas sim, perceber que as representações formam para nós, um tipo de realidade.

A segunda função é a prescritiva. As representações são prescritivas, pois se impõem sobre nós, com uma força dominante. Tal força provém tanto da estrutura social como de uma tradição que determina o que deve ser pensado, antes mesmo de começarmos a pensar, para tudo se encontra uma resposta pronta.

Ademais, o autor nos revela que, "enquanto essas representações que são partilhadas por tantos penetram e influenciam a mente de cada um, elas não são pensadas por eles; melhor, para sermos mais preciosos, elas são repensadas, recitadas e reapresentadas" (MOSCOVICl, 2015, p. 37). Pode-se assim perceber, que a representação que temos de algo, não está relacionada diretamente a nossa maneira de pensar, isso porque nosso modo de pensar depende de tal representação, que é imposta, transmitida e é produto de uma série de 
mudanças ocorridas no decorrer do tempo, e de diversas gerações. Nesta perspectiva:

todos os sistemas de
classificação, todas as
imagens e todas as
descrições que circulam
dentro de uma sociedade,
mesmo as descrições
cientificas, implica um elo
de prévios sistemas e
imagens, uma
estratificação na memória
coletiva e uma reprodução
na linguagem que,
invariavelmente, reflete
um conhecimento anterior
e que quebra as amarras
da informação presente
(2015, p. 37).

Por serem elaboradas e compartilhadas socialmente, as representações exercem forte influência na forma como os grupos sociais e também os indivíduos observam a realidade, se comunicam e agem (GUIMARÃES, 2005). As representações exprimem como um grupo de pessoas interagem com um determinado objeto social, como direcionam e orientam a comunicação e as relações com o mundo e com os indivíduos. Ademais, oferecem referencias para a interpretar a realidade, além de favorecer a construção de valores, necessidades, interesses de um mesmo grupo.

Conforme a autora, grupos diferentes interpretam um mesmo objeto segundo diversas perspectivas, cada qual à sua maneira. Nesse sentido, em cada grupo, "o objeto apreendido passa a fazer parte das conversas e aparece na forma de frases, visões, jargões, ditados, preconceitos, estereótipos, soluções, etc, tendo um efeito de realidade para o indivíduo" (GUIMARÃES, 2005, p. 35).

De acordo com Moscovici (2015) as representações não são criadas por um indivíduo de forma isolada, as pessoas e os grupos vão criando as representações no decorrer da convivência e da comunicação. Após criadas, tais representações ganham vida própria, circulam, se entrecruzam e possibilitam o surgimento de novas representações, enquanto as velhas desaparecem.

As representações orientam as ações, enquanto reconstroem os componentes do meio no qual o comportamento surge, incluindo-o a uma série de significações em que pertence o objeto. Para Jodelet (1986) apud Guimarães (2005, p. 38), na representação, existem cinco características essenciais:

- Sempre é a
representação de um
objeto;
- Tem um caráter de
imagem e a propriedade
de poder modificar o
sensível e a ideia, a
percepção e o conceito;
- Tem um caráter
simbólico e significante;
- Tem um caráter
construtivo;
- Tem um caráter
autônomo e criativo;

Segundo Moscovici (2015), há dois processos fundamentais que mostram como o social transforma o conhecimento em representação e como esta, por sua vez, transforma o social. Através de tais processos, emergem as representações sociais. São eles, a ancoragem e a objetivação.

O primeiro mecanismo
tenta ancorar ideias
estranhas, reduzi-las a
categorias e imagens
comuns, colocá-las em um
contexto familiar [...] o
objetivo do segundo
mecanismo é objetivá-los,
isto é, transformar algo
abstrato em algo quase
concreto, transferir o que
está na mente em algo
que exista no mundo físico
(MOSCOVICl, 2015, p. 60 -
$61)$

A ancoragem "é o processo que transforma algo estranho e perturbador, que nos intriga, em nosso sistema particular de categorias e compara com um paradigma de uma categoria que nós pensamos ser apropriada" (MOSCOVICI, 2015 , p. 61). De acordo com o autor, ancorar é classificar, dar nomes às coisas. Algo sem classificação e sem nome é considerado, pelas nossas estruturas de pensamento, estranhas e inexistentes. Nós apresentamos certa resistência, distanciamento do que não é familiar. Somente a partir do momento em que avaliamos, categorizamos dado objeto, podemos reproduzilo como uma cópia de um modelo que consideramos familiar. Assim, "a representação é 
fundamentalmente, um sistema de classificação e de denotação, de alocação de categorias e nomes" (p.62). Em síntese, dois aspectos importantes da ancoragem das representações são classificar e atribuir nomes.

Segundo Guimarães, o processo de ancoragem configura-se pela "constituição de uma rede de significações em torno do objeto, relacionando-o a valores e práticas sociais. Tratase da inserção de um conhecimento em um pensamento já elaborado" (2005, p. 40). Para a autora, a ancoragem é o processo de atribuição de sentido, deste modo, os valores sociais influenciam fortemente na criação dessa rede de significados ao redor do objeto.

Articulando-se diretamente com a objetivação, a ancoragem, articula três funções básicas: a função cognitiva de integração das novidades, função de interpretação da realidade e orientação de condutas e relações sociais (JODELET apud GUIMARÃES, 2005, p.40).

Adicionalmente, "a objetivação une a ideia de não familiaridade com a de realidade, torna-se verdadeira essência da realidade" (MOSCOVICl, 2015, p. 71). O autor aponta que objetivar é descobrir a qualidade exata de uma ideia; é reproduzir um conceito em uma imagem.

De acordo com Guimarães, o processo de objetivação caracteriza-se "pela transformação de conceitos e ideias para esquemas ou imagens concretas, ou seja, trata-se da construção formal de um conhecimento" (2005, p.39), transformando aquilo que é abstrato em algo concreto para o sujeito.

\section{Identidade e representações sobre a profissão docente}

Atualmente evidencia-se no cenário acadêmico, na sociedade e na mídia, uma grande discussão a respeito da identidade docente. Uma vez que entender o processo de constituição da identidade docente é uma tarefa muito complexa, e que passa pela compreensão de que ela foi sendo constituída por múltiplos contextos: sociais, históricos, culturais, políticos, dentre outros. Deste modo, é necessário considerar que esse processo de identificação com uma profissão por um determinado grupo, é um fenômeno histórico, portanto, como tal está sujeito a transformações.

Para Marcelo (2009), a reflexão sobre identidade profissional docente é muito relevante, pois, é por meio de nossa identidade, que nós nos percebemos, nos vemos e queremos que nos vejam.

De acordo com Pimenta (1997, p. 6), "a identidade não é um dado imutável. Nem externo, que possa ser adquirido. Mas, é um processo de construção do sujeito historicamente situado". Para a autora:

Uma identidade
profissional se constrói,
pois, a partir da
significação social da
profissão; da revisão
constante dos significados
sociais da profissão; da
revisão da tradições.
Como, também, da
reafirmação de práticas
consagradas
culturalmente e que
permanecem
significativas. Práticas que resistem a inovações, porque estão prenhes de saberes válidos às necessidades da realidade. Do confronto entre as teorias e as práticas, da análise sistemática das práticas à luz das teorias existentes, da construção de novas teorias, constróise, também, pelo significado que cada professor, enquanto ator e autor confere à atividade docente no seu cotidiano a partir de seus valores, de seu modo de situar-se no mundo, de sua história de vida, de suas representações, de seus saberes, de suas angústias e anseios, do sentido que tem em sua vida: o ser professor (PIMENTA, 1997, p. 7).

Nesta perspectiva, é necessário entender o conceito de identidade profissional como uma realidade, por meio do qual espera-se que o profissional docente evolua e se desenvolva, tanto pessoal como coletivamente. Há que se considerar, portanto, que identidade é um algo que se desenvolve durante toda a vida, e que ocorre no campo da intersubjetividade, constituindo-se como um processo em evolução, 
de interpretação de si próprio como pessoa dentro de algum contexto.

Do mesmo modo, Marcelo (2009) citando Lasky (2005), discorre que a identidade profissional, é uma construção do "si mesmo", que no decorrer da carreira evolui, podendo ou não se influenciar pela escola, pelas reformas ou por contextos políticos. Compreende ainda o compromisso, a disposição para aprender a ensinar, as crenças, os valores, o conhecimento dos conteúdos e do ensino, e também a vulnerabilidade profissional.

Sabe-se que a profissão docente não é inata, mas sim construída e reconstruída constantemente. Tal construção comporta vivências e saberes pertencentes a cada pessoa, e que se estende durante toda a formação. Diante disso, pressupõe-se que nesse processo há reconstrução das representações que a todo o momento se confrontam com as expectativas e necessidades, refletindo assim os medos, inseguranças, angústias frente a prática docente (PETRENAS; MOKWA; GONINI, 2009).

Em sua trajetória, o curso de Pedagogia apresentou avanços e retrocessos no processo de profissionalização docente ${ }^{1}$, e influenciou, de forma expressiva, na constituição da identidade docente. Dessa forma, se configura também como espaço de construção e reconstrução de representações sociais, processo esse que pode ainda se refletir no exercício da futura profissão.

De acordo com Trevisan e Gebran (2017, no prelo), muitas pesquisas mostram a confirmação de que não é possível alcançar mudanças na educação, se a forma como os professores pensam for ignorada, assim como a forma como atuam, como representam seu trabalho e como as condições desse trabalho lhes permitem se posicionarem, criticamente, diante das práticas educativas propostas pelas reformas.

Ademais, as autoras discorrem, que quando os sujeitos não têm consciência de suas representações, atuam guiados por práticas formadas culturalmente e historicamente, sem, no entanto, reconhecerem ou identificarem seus efeitos de sentido e de pertinência na sociedade.

\footnotetext{
${ }^{1} \mathrm{O}$ Movimento de profissionalização docente é complexo e envolve grupos e entidades diversificadas, incluindo a participação ativa de entidades sindicais e associações estudantis e científicas. Exige ainda políticas públicas adequadas em consonância com as demandas formativas dos docentes e com as necessidades da escola e as exigências da cultura contemporânea. Para saber mais consultar: TREVISAN, Zizi; DIAS, Carmen Lúcia (org). Profissionalização: construção do conhecimento e da identidade docente. 1 ed. Curitiba, PR: CRV, 2012.
}

Nesta perspectiva, tais representações podem funcionar como estereótipos, a respeito do que os professores devem fazer, enquanto as razões e críticas permanecem ocultas, bem como as verdadeiras justificativas políticas e ideológicas de suas ações.

Dubar (2005) mostra que a identidade humana não é dada no nascimento, pelo contrário, ela é construída na infância, devendo desde então, ser reconstruída no decorrer da vida. Da mesma forma, Nóvoa (1992) explica que a identidade envolve um lugar de lutas, de conflitos, onde são construídas as maneiras de ser e de estar na profissão. Diante disso, é necessário refletir sobre o papel das representações sociais na construção da identidade docente e como a formação inicial poderá contribuir nesse processo.

Adorno (1995) citado por Trevisan e Gebran (2017, no prelo), ressalta que uma formação inicial sólida, baseada no exercício contínuo de uma visão humanística, entendida como um processo que possibilita aos sujeitos o convívio em sociedade, permite o desenvolvimento da consciência crítica e, assim, de adquirir maior autonomia. Por conseguinte, promove $\mathrm{o}$ fortalecimento da identidade profissional

Diante disso, as autoras suscitam que o processo de construção da identidade do profissional docente, relaciona-se com a autoimagem, a autobiografia, e com as representações que os professores fazem de si mesmos e dos outros, em seu ambiente laboral. Afirmam que "é na interação com o mundo e com os parceiros que o sujeito elabora o conhecimento crítico-ideológico e vai se socializando, construindo valores e se apropriando das ideias que circulam na sociedade" (p. 9).

Deste modo, na busca por explicações para a realidade que nos envolve, e por respostas a questões que envolvem a humanidade, criamos as representações sociais. Configurando-se assim, como formas de explicar não somente a realidade, mas também os objetos sociais, mediada pela linguagem.

Madeira (1998) apud Guimarães (2005) afirma que tomar as representações sociais como categoria de análise dos estudos no meio educacional, atribui relevância teórica e histórica, em um sentido social e político, se o que se quer é descobrir, conhecer, explicar de modo que desapareçam as certezas já estabelecidas. 
Mazzotti (2008) expõe que a intenção de promover mudanças por meio da educação exige a compreensão dos processos simbólicos que ocorrem na interação educativa. Ou seja, para que a pesquisa educacional tenha maior impacto sobre a prática educativa, ela deve adotar "um olhar psicossocial", que ora, preenche o sujeito social com um mundo interior, ora, restitui o sujeito individual ao mundo social (MOSCOVICl, 1990 apud MAZZOTTI, 2008).

Desse modo, o autor observa no estudo das representações sociais um caminho promissor para atingir os propósitos educacionais. Surge então, a necessidade de investigar como se formam e como funcionam os sistemas de referência que os sujeitos utilizam para classificar pessoas e grupos e para interpretar os acontecimentos da realidade. Devido às relações com a linguagem, a ideologia e com o imaginário social e, sobretudo, devido ao papel na orientação de condutas e das práticas sociais, as representações sociais compõem elementos fundamentais à análise dos mecanismos que interferem na construção da identidade docente bem como na eficácia do processo educativo.

Abric (1998) apud Guimarães (2005), propôs quatro funções para as representações sociais. A compreensão de tais funções pode orientar a análise do que acontece com o processo de ensino-aprendizagem quando entra em confronto com as informações e/ou situações que vão contra o que temos de referência. A saber:

Funções do saber: a compreensão e explicação da realidade: conhecimentos são adquiridos e integrados ao que é assimilável e compreensível,

coerentemente ao seu funcionamento cognitivo e seus valores, facilitando a comunicação social.

Funções identitárias: definem a identidade e protegem a especificidade dos grupos. Isso permite que os indivíduos e grupos formem identidade pessoal e social compatível com sistemas de normas e valores social e historicamente determinados.
Funções de orientação: as representações sociais guiam os comportamentos e as práticas. Elas intervêm na definição da situação. Produzem também sistemas de antecipação e de expectativa que orientam a seleção e filtragem de informações interpretações, conformando a realidade à representação. A representação prescreve comportamentos ou práticas obrigatórias e normatiza as ações.

Funções justificatórias: representações sociais permitem que as tomadas de posição sejam explicadas e justificadas após sua ocorrência (grifos nossos) (ABRIC 1998, apud GUIMARÃES, 2005, p. 5354).

Tais funções das representações sociais podem proporcionar aos formadores informações que orientarão a escolha dos conteúdos, das metodologias, bem como das práticas pedagógicas e de avaliação, pelas quais os alunos serão submetidos no processo de ensino-aprendizagem. Ademais, Guimarães (2005), discorre que as funções permitem a compreensão e o conhecimento de meios para intervir da forma mais pertinente e adequada possível durante o processo de (trans)formação de atitudes, valores e crenças nos educandos, visando o objetivo de constituir a função educativa da educação.

De acordo com Marcelo (2009), os futuros professores não são como 'vasos vazios' quando ingressam na instituição de formação inicial docente, possuem suas ideias e crenças já estabelecidas a respeito do que é ensinar e aprender. Deste modo, observa-se que as crenças são como premissas que os indivíduos mantem em relação ao que é considerado como verdade. Tais crenças desempenham duas funções no processo de ensino-aprendizagem: a) influenciam no modo como os professores aprendem; b) interferem nos processos de mudança que os professores possam tentar (RICHARDSON, 1996 apud MARCELO, 2009). 
Nesta perspectiva, os professores que entram nos cursos de formação, arraigados por suas crenças pessoais em relação ao ensino, fazem uma imagem de si mesmo como professor a partir das experiências de quando era aluno. São crenças e imagens que dificilmente são alteradas, perpassam a formação e reflete na prática pedagógica. A esse respeito, Feiman (2001) apud Marcelo (2009), explica que as imagens e crenças que os professores em formação carregam ao iniciarem a formação inicial agem como filtros através dos quais eles "dão sentido aos conhecimentos e experiências com que se deparam. Mas também podem atuar como barreira à mudança, limitando as ideias que os alunos podem vir a desenvolver sobre 0 ensino" (p. 117).

Mazzotti (2007) concorda quando Perrenoud (1999) afirma que a realidade da educação não se modifica somente por meio de boas ideias, mas sobretudo através de mudanças das representações, atitudes, valores e da própria identidade dos indivíduos que permeiam todo o processo educativo. Deste modo:

o conhecimento das
representações sociais do
professor como um
conjunto organizado de
julgamentos, atitudes e
informações elaborados a
respeito de um objeto
social com o objetivo de
orientar e justificar
práticas - assume
relevância para orientar
políticas voltadas para a
formação inicial e
continuada do professor
(MAZzOTTI, 2007, p. 581).

Assim, é possível considerar que o conhecimento das representações sociais possibilita analisar como se desenvolve 0 processo educativo nos sistemas de ensino, não somente esclarecendo e/ou levantando expectativas, mas também fornecendo elementos para que se reflita sobre as condições do trabalho docente, e as políticas públicas que $o$ regulam.

Como já mencionado, desde a formação inicial, os futuros docentes trazem consigo próprias representações e de alguma as processa. Tais representações estão fincadas nos diversos momentos vivenciados no processo de escolarização. Para Nóvoa (1999), é fundamental que as instituições formadoras considerem essas representações, de ordem social e pessoal, possibilitando ainda que os futuros docentes conheçam melhor a si próprios e a realidade da profissão que irão assumir.

Conforme Penin; Roberti (2013) a formação para docência deve favorecer um movimento de discussões para reelaboração dos conhecimentos "que requer a aceitação das crenças e representações que os alunos têm do ensino, bem como de suas vivências na formação inicial e anteriores a ela, como constituintes do saber profissional" (p. 168).

Cabe considerar ainda, segundo Jodelet (2001), que as representações sobre o trabalho docente que os professores ou futuros professores possuem, podem coexistir com os conhecimentos que receberam (ou recebem) em sua formação inicial, como também se constituírem em obstáculos ou mecanismos de resistência para novos conhecimentos. Essas mesmas representações podem impedir mudanças mais efetivas, ficando apenas na superfície, sem possibilitar que haja uma transformação capaz de atender as atuais demandas formativas e educacionais (ABRIC, 1998, 2000).

Em razão disso, considerar e refletir sobre o papel das representações sociais no processo de construção da identidade docente dos professores em formação, é um tema que precisa ser mais debatido.

\section{CONSIDERAÇÕES FINAIS}

Numa sociedade na qual o conhecimento é um dos principais valores, assume relevância o nível de formação de seus cidadãos, bem como a capacidade de inovação e empreendedorismo que possuem. No entanto, esse conhecimento não é pronto e acabado, ou seja, implica na necessidade de cidadãos e profissionais em geral atualizarem, constantemente, suas competências e saberes, em um processo de formação permanente.

Nesse quadro, o professor assume relevância, uma vez que, evidencia-se, cada vez mais, o papel fundamental que possui na qualidade da educação e, portanto, como elemento essencial para a sociedade do conhecimento. Esse fato, deverá se configurar como um peso muito grande na constituição da identidade docente e passa, impreterivelmente, pela necessidade da valorização docente, tanto 
pelos diversos segmentos da sociedade civil como pelo poder público.

Diante disso, é possível afirmar que necessitamos políticas públicas sérias e efetivas para que a formação inicial, aliada à formação continuada do profissional docente, assegure o desenvolvimento de competências e saberes que irão necessitar em sua trajetória profissional, considerando o grau de complexidade dos desafios que, certamente, irão se deparar. Há que se considerar que a sociedade carece de bons professores, cuja prática profissional esteja de acordo com os padrões profissionais de excelência, capazes de garantir o compromisso em relação ao direito que os alunos têm de aprender com qualidade (MARCELO, 2009).

Além disso, cada setor sociocultural tem um sistema de representação sobre os diferentes aspectos da vida. Em nosso meio socioprofissional e acadêmico, não é diferente, também construímos nossas próprias representações e por meio delas, construímos as práticas e impomos aos alunos formas de aprendizagem, partindo do pressuposto que sabemos o que é melhor para eles. No entanto, é fundamental considerar as representações sociais dos nossos alunos, de suas famílias e as nossas próprias, sobre os conhecimentos e valores veiculados na escola, no sentido de superar os problemas educacionais e caminharmos para uma maior valorização docente.

Desta forma, um dos grandes desafios que se coloca hoje é tornar os cursos de formação inicial um espaço propício à constituição de uma identidade docente transformadora, ou seja, que assuma o compromisso de pertencimento a uma profissão, que almeja a emancipação social e humana de todos os alunos.

\section{REFERÊNCIAS}

ABRIC, J.C. A abordagem estrutural das representações sociais. In: MOREIRA, A. S. P. e OLIVEIRA, D.C. Estudos interdisciplinares sobre representações sociais. Goiânia, AB Editora, 1998.

OLIVEIRA, D. C. de (Orgs.) Estudos

interdisciplinares de representação social. 2 ed. Goiânia: AB, 2000. p. 27-38.

CIAMPA, A. da C. A estória do Severino e a história da Severina. São Paulo: Brasiliense, 2007.
DUBAR, C. A socialização: construção das identidades sociais e profissionais. São Paulo: Martins Fontes, 2005.

DUVEEN, Gerard. Introdução: O poder das ideias. In: MOSCOVICl, Serge. Representações sociais: investigações em psicologia social. 11. ed. Petrópolis: RJ: Vozes, 2015.

TREVIZAN, Zizi; GEBRAN, R. A.. As representações sociais na construção da identidade profissional e do trabalho docente. Revista Acta Scientiarum. Education, 2017. No prelo.

GUIMARÃES, C. M. Aplicabilidade das Representações Sociais ao Estudo de Fenômenos Educacionais - mudar as práticas de formação para mudar as práticas educativas do profissional de educação infantil. In: GUIMARÃES, C. M. (org) Perspectivas para educação infantil. Araraquara: Junqueira \& Marin, 2005.

IMBERNÓN, F. Formação permanente do professorado: novas tendências. São Paulo: Cortez, 2009.

JODELET, Denise. Representações Sociais: um domínio em expansão. In: JODELET, D. (Org.). As representações sociais. Ed. UERJ. Rio de Janeiro, $2001 . \quad$ Disponível em: https://pt.scribd.com/doc/61566294/Representa coes-Sociais-Cap-01-Jodelet. Acesso em: 19 de abr. 2015.

MARCELO, Carlos. A identidade docente: constantes e desafios. Revista Formação Docente Belo Horizonte, v. 1, n. 1, p. 109-131, ago./dez. $2009 . \quad$ Disponível em http://formacaodocente.autenticaeditora.com.Tr adução: Cristina Antunes. Acesso em: 06 de abr. 2016.

MAZZOTTI, Alda Judith Alves. Representações da identidade docente: uma contribuição para a formulação de políticas. Ensaio: Aval. Pol. Públ. Educ., Rio de Janeiro, v. 15 , n. 57, p. 579-594, out./dez. 2007.

MAZZOTTI, Alda Judith Alves. Representações sociais: aspectos teóricos e aplicações à educação. Revista Múltiplas Leituras, v.1, n. 1, p. 18-43, jan./jun. 2008. Disponível em: https://www.metodista.br/revistas/revistas- 
ims/index.php/ML/article/view/1169. Acesso em: 01 fev. 2016.

MORGADO, J. C. Currículo e profissionalidade docente. Portugal: Porto, 2005.

MOSCOVICl, Serge. Representações sociais: investigações em psicologia social. 11. ed. Petrópolis: Vozes, 2015.

NÓVOA, António. (org.). Profissão Professor. Porto: Editora Porto, 1999.

NÓVOA, António. Formação de professores e profissão docente. In: NÓVOA, António (coord.) Os professores e a sua formação. 1992.

PETRENAS, Rita de Cássia; MOKWA, Valéria Marta N.; GONINI, Fátima Coelho. Representações sociais de alunos do curso de pedagogia: expectativas em relação a formação docente. Revista Ibero Americana de Estudos em Educação, v. 4, n. 2, 2009.
Disponível

em: http://seer.fclar.unesp.br/index.php/iberoameric ana/article/view/2781. Acesso em: 01 fev. 2016.

PIMENTA, Selma G. Formação de Professores Saberes da docência e identidade do professor. Nuances, v.3, set. 1997. Disponível em: http://revista.fct.unesp.br/index.php/Nuances/ar ticle/download/50/46. Acesso em: 20 jun. 2015.

Recebido para publicação em: 24/04/2016

Revisado em: 27/04/2016

Aceito em: 30/04/2016 